work-up before initiating treatment, defines the treatment goals, and improves control. The use of a problem-orientated summary card in addition seems to achieve most of the objectives attempted in the computer-held record system. For research perhaps manual handling of notes is still necessary, but recall of information is much simplified, as compared with unstructured notes.

The problem-orientated record system has the advantage that it is very inexpensive and can be used by both general practices and hospitals which have no access to computers.

Abbot's Langley,
Herts

P R V TOMSON

SIR,-In the discussion of their work on computer-held records of hypertensive patients Dr C J Bulpitt and his colleagues (20 March, p 677) compare their computer system with the clerical retrieval from standard notes. However, many of the advantages they have found using the computer could be achieved using a simpler approach-for example, punched feature cards. ${ }^{1}$ We have used punched feature cards in a general practice of 10000 patients for three years ${ }^{2}$ and, should it prove necessary, they can be used as an input to a computer. ${ }^{3}$

The false logic of "a computer can solve our problems, therefore we should use a computer to solve our problems" appears to be all too common. Perhaps more attention should be paid to simple, less expensive, and more flexible information handling systems, of which punched feature cards are an outstanding example.

Centre for Medical Education, University of Dundee

\section{RONALD HARDEN}

Bearsden,

KENNETH HARDEN

Glasgow

Harden, R McG, et al, British fournal of Hospital Medicine, 1975, 13, 195

Harden, K A, Harden, R McG, and Reekie, D, British Medical fournal, 1974, 2, 162.

Royal College of General Practitioners, $1975,25,143$.

\section{Recurrent haematuria}

SIR,-The paper by Dr J Michael and his colleagues from St Thomas's Hospital on unexplained recurrent haematuria (20 March, p 686) comes as a welcome addition to the literature on this important subject. However, one or two points deserve comment.

I have never questioned the value of renal biopsy in the syndrome of recurrent or persistent haematuria, only its justification and practicability as a routine in such patients. Unexplained haematuria remains a large group in most disease indices, being second in magnitude (25 cases) in Burkholder's group of haematuria cases ${ }^{1}$ and making up $5-10 \%$ of all patients with haematuria in the Manchester review. ${ }^{2}$ Leaving aside economic and temporal factors it seems unlikely, should this incidence be reflected nation-wide, that facilities exist for the efficient performance of renal biopsy and the accurate interpretation of the histological and immunofluorescent findings in every patient falling into this group. The pursuit of a diagnosis, especially if it prevents needless over-investigation, is to be applauded; it was Burkholder's contention-rightly so, I feel- that invasive investigations with a recognised morbidity which do not lead to any significant change in patient treatment might be open to criticism.

Furthermore, the average age in the $S t$ Thomas's group was 25 years-an age group in which renal biopsy might be expected to yield a high incidence of abnormalities reflecting the high incidence of so-called focal nephritis in young adults with haematuria. The average age in the Manchester review was 50 years, in which group the search for incipient malignant disease is a more significan problem and in which renal biopsy might not play such a useful role.

This said, however, the results from $S t$ Thomas's certainly complement those from other centres investigating the younger groups of recurrent haematuria and, with those of Higgins and $\mathrm{Aber},{ }^{3}$ seem to indicate the diag nosis, in the young male patient with this complaint, of mesangial IgA nephropathy, with its apparent independence from the haematuria/loin pain syndrome, of possible renovascular origin, occurring more commonly in the female. This may well represent significant step forward in the clarification of this important disease complex and its management.

\section{PATRICK H O'ReILLY}

Manchester Royal Infirmary,

hester

Burkholder, G V, et al, fournal of the American Medical Association, 1969, 210, 1729.

(1974 (U)

Urology, 1974, 46, 601 .

\section{Propranolol and the nephrotic syndrome}

SIR,-In a recent report (12 April 1975, p 68) my colleagues and I described a patient who had developed the nephrotic syndrome in association with practolol therapy. In the same patient propranolol was substituted for practolol in a dosage of $40 \mathrm{mg}$ daily for 10 months and $160 \mathrm{mg}$ daily for another six months. Vague circumscribed psoriasiform skin lesions on the arms and a proteinuria of $2 \mathrm{~g} / 24 \mathrm{~h}$ were then detected. No urinary protein had been detected on routine examination during the previous months. The propranolol was stopped, but four weeks later the patient developed a severe normotensive nephrotic syndrome with a proteinuria of $21 \mathrm{~g} / 24 \mathrm{~h}$, urinary casts, no excess of urinary red or white cells, a creatinine clearance of $70 \mathrm{ml} / \mathrm{min}$, and a serum albumin concentration of $26 \mathrm{~g} / 1$. Tests for antinuclear factor in the serum were negative.

Treatment with prednisolone, initially $60 \mathrm{mg}$ daily, was instituted six weeks after stopping the propranolol therapy because of persistent severe proteinuria. After three weeks the urine contained only a trace of protein and the serum albumin level was $35 \mathrm{~g} / 1$. Two weeks later the urinary protein was quantitatively normal and the creatinine clearance was $82 \mathrm{ml} / \mathrm{min}$. The rash had also resolved.

It was assumed that the propranolol had induced a minimal-change glomerulonephritis, as the practolol had done. This diagnosis was not confirmed by a second renal biopsy, although it was supported by the excellent and swift improvement with prednisolone. $\mathrm{Al}$ though practolol and propranolol are different chemically, they both act as beta-blockers and, in this man's case, they both appear to be capable of inducing a nephrotic syndrome.

Department of Nephrology, Hull Royal Infirmary (Sutton)
Hull

M J FARR

\section{Bottle-feeding and tummy-ache in infants}

SIR,-Newborn babies commonly have tummy-ache. The infant cries incessantly, will not be comforted, flexes his legs, and continually seeks the breast, although his sucking is frequently interrupted by spasms of distress The syndrome is conventionally ascribed (without evidence) to "wind," and since it is maximal at around one week of age-shortly after discharge from hospital-tends not to come to the notice of the doctor. The mother and her advisers frequently interpret the signs as resulting from under-feeding and hunger, and this is a major factor in the customary decision to abandon breast-feeding. ${ }^{1}$

Virtually all hospital-born babies receive feeds of cow's milk for the first 1-3 nights of life, even if they are subsequently to be breast-fed. Cow's milk is antigenic and evokes an antibody response in normal bottle-fed neonates. ${ }^{2}$ A local immune response in the gut would be associated with hyperplasia of the mesenteric lymph nodes and Peyer's patches, with inflammation and hyperperistalsis leading perhaps, in exceptionally severe cases, to intussusception. The timing of the syndrome is just right for primary immune response.

Total avoidance of cow's milk in neonatal life has been advocated ${ }^{3}$ as a means of preventing atopy. I suggest that it would also avoid "wind" and greatly increase the likelihood of successful breast-feeding.

DAVID FREED

Immunology Laboratories,

Dacteriology and Virology,

University of Manchester 'Davies, D P, and Thomas, C, Lancet, 1976, 1, 420.
Truelove, S C, and Jewell, D P, in Clinical Aspects of
Immunology, ed P G H Gell, R R A Coombs, and
P J Lachmann. Oxford, Blackwell, 1975.
3 Soothill, J F, et al, British Society for Allergy and
Clinical Immunology, Oxford meeting, 13 Decem-
ber 1975 .

\section{Amoebic meningoencephalitis in Britain}

SIR,-Dr J L Griffin (17 January, p 153) has suggested that in our case of amoebic meningoencephalitis ${ }^{1}$ an acanthamoeba (which was not isolated) must have been the primary pathogen, the Naegleria gruberi which was isolated from the cerebrospinal fluid $(\mathrm{CSF})^{2}$ being a secondary invader.

We agree that in the CSF the amoebae which were seen resembled acanthamoebae more than naegleriae, although naegleriae can move slowly and produce spiky pseudopods. ${ }^{3}$ Dr Griffin suggests that culture for acanthamoebae from the CSF should have been done immediately. In fact, although not mentioned in our papers, this was done in this laboratory but no amoebae were isolated. Immediately after collection the first specimen of CSF from case 1 in which amoebae were seen (two days after admission) was inoculated on to klebsiella-agar plates and into HeLa cell cultures, both of which had previously been found suitable in this laboratory for the growth of acanthamoebae. The surface of the agar was of a drynes known to be suitable for the growth of acanthamoebae, although this degree of dryness was found subsequently to be unsuitable for the growth of naegleriae. The day after collection this CSF 
was also inoculated intracerebrally into a strain of mice known to be susceptible to acanthamoebae, but amoebae were not isolated.

Dr Griffin also suggests that repeated nasopharyngeal specimens should have been examined for acanthamoebae. In fact this also was done. Nose and throat swabs taken two days after admission and two and four days later were inoculated into HeLa cell cultures, on to klebsiella-agar plates, and intracerebrally into mice, again with negative results.

It is possible, as Dr Griffin suggests, that these cultures of $\mathrm{CSF}$ and nasopharyngeal secretions were negative because the sulphadiazine received by the patient for two days before the specimens were taken had inactivated the amoebae. However, the amoebae were seen to be still moving, although very sluggishly, in a specimen of CSF taken four days after the first, after the patient had received both sulphadiazine and amphotericin B.

The high cell count in the CSF is more typical of naegleria than of acanthamoeba infection. Dr Griffin suggests that $N$ gruberi, which is sensitive to febrile temperatures, would cause little damage in a patient with a fever. In fact our patient had a fever of $39 \cdot 1{ }^{\circ} \mathrm{C}$ on admission, but thereafter his temperature never rose above $37^{\circ} \mathrm{C}$.

There is thus no evidence for Dr Griffin's theory that the $N$ gruberi was not the primary pathogen in this case.

D C WARHURST A P C H ROOME S K R CLARKE

Public Health Laboratory,

Bristol

1 Apley, J, et al, British Medical fournal, 1970, 1, 596. Saygi, G, Warhurst, D C, and Roome, A P C H, Proceedings of the Royal Society of Medicine, 1973,
66, 277. Schuster, F L, and Rechthand, E, and Chemotherapy, 1975, 8, 591 .

\section{Squints}

SIR,-Mr B Harcourt (20 March, p 703) rightly mentions in his conclusions that squints require early diagnosis and early investigation. Neglect of this, he points out, may not only lead to permanent disability but also fail to unmask serious disease.

One obstacle to this desirable goal is often the waiting list for outpatient appointments and another, partly for this reason, is the reluctance of the doctor to make a referral until he is sure the squint is "real," hence producing the very delay which is detrimental. In some areas, notably the London Borough of Barnet, this difficulty has been overcome by a very successful arrangement whereby the orthoptist in the locally dispersed children's eye clinics sees any child from any doctor in the area who is uncertain and then refers those who require it to the ophthalmologist. This system has resulted in much earlier diagnosis and treatment of real squints and spared many a mother the wearisome and pointless business of having to attend hospital because her child has a broad nose. It also brings to light visual problems in siblings and the earlier diagnosis of conditions predisposing to squints such as high hypermetropia or anisometropia.

One other point which improves the defaulting rate at an early stage is the use of $0.1 \%$ hyoscine drops in place of several days of atropine. This is as powerful a cycloplegic and only requires one hour to work, obviating the necessity of a second visit and, in some cases, the destruction of a happy relationship between mother and baby.

\section{Guy's Hospital,}

P A GARDINER

London SE1

SIR,-As with the other papers in your series "Problems of childhood", Mr Brian Harcourt's article on squint (20 March, p 703) is commendable for its clarity, conciseness, and clinical relevance. He rightly stresses the importance of early diagnosis and treatment.

However, although glad to learn that squint surgery "rarely requires over three days in hospital," I feel that it is insufficient to state that it "is not particularly uncomfortable or unsettling even for very young children." Where preschool children have to be admitted to hospital, sadly it still seems necessary to emphasise the importance of their mothers being admitted with them. A recent paper by Douglas $^{1}$ reveals not only that hospital admission without the mother can result in disturbed behaviour in preschool children on return home but also that there is a significant increase in problems of behaviour and learning during the adolescence of these children. Other writers ${ }^{2}$ have shown us how the concept of the child being "settled" in hospital can be misunderstood.

Where the mother cannot accompany the child Vaughan, ${ }^{3}$ who reported on 40 children (mean age 5.9 years) in hospital for five days for correction of strabismus, described a deliberate policy of discussing their fears with the children and explaining the procedures, which mitigated some of the adverse psychological effects of the experience. Other methods have also been described. ${ }^{4}$ Vaughan also reviewed $^{6}$ the psychiatric causes of squint, which were not referred to in Mr Harcourt's article.

\section{ANTHONY G CARROLI}

Department of Child and

Family Psychiatry,

Regional Hospital

' Douglas, J W B, Developmental Medicine and Child Neurology, 1975, 17, 456. Vol. 17, No 4, August,

${ }^{2}$ Wolff, in Children under Stress, $\mathrm{p} 90$. Harmondsworth, Pelican Books, 1973.

- Becker, R D, Internat nal fournal of Child Psycho-

therapy, 1972, 1, 65.

MacCarthy, D, Developmental Medicine and Child
Neurology, 1974, 16, 279.
Vaughan, G F, in Little Club Clinics in Developmental Vaughan, G F, in Little Club Clinics in Developmental
Medicine No 9, ed V H Smith. London, Heinemann, 1963.

Occupational hazard in preparation of polyacrylamide gels

SIR,-Polyacrylamide gel electrophoresis is used very widely for the analysis of proteins. The toxicity of the acrylamide monomer is well known. ${ }^{12}$ We have, however, encountered recently a case of an acute allergic response to one of the reagents used in the preparation of polyacrylamide gels. The substance, $N, N, N^{\prime} N^{\prime}$-tetramethylenediamine (TEMED), $\left(\mathrm{CH}_{3}\right)_{2} \mathrm{NCH}_{2} \mathrm{CH}_{2} \mathrm{~N}\left(\mathrm{CH}_{3}\right)_{2}$, is used to promote polymerisation of the gel..$^{34}$

A research worker in this laboratory, in his late twenties and otherwise in good health, complained of insomnia which was associated with intense generalised pruritus. Skin testing showed that the agent responsible was TEMED. Five millilitres of TEMED was applied to the subject's forearm; within 30 seconds local vasoconstriction occurred and was followed by a suffused vasodilatation proximal to the site of application. Within 2030 minutes the vasodilation had spread to the skin of the face and giant urticarial weals were apparent. Intense generalised pruritus and a pricking sensation of the conjunctivae lasted for approximately 12 hours. The application of reagent to the forearm of a control subject elicited no reaction.

The reaction could be adequately controlled with chlorpheniramine maleate. The allergic response occurred probably as the result of a type I hypersensitivity reaction (anaphylactic, reagin-dependent ; classification of Gell et $\mathrm{al}^{5}$ ) mediated by the TEMED acting as a hapten and involving homocytotropic IgE antibodies. Satisfactory control was achieved by asking non-sensitive colleagues in the laboratory to handle the material in a fume hood.

The problem of toxic and allergic responses to materials found in research laboratories is an area in which recent legislation has defined the responsibilities of both employer and employee more clearly than in the past. Potential allergens commonly found in research laboratories include small-molecule sensitizers, of which TEMED is an example, and purified enzymes used for analytical purposes.

\section{R A KLEIN}

Medical Research Council Biochemical

Parasitology Unit,

Molteno Institute,
University of Cambridge

' Fullerton, P M, Fournal of Neurology, Neurosurgery and Psychiatry, 1969, 32, 186.

Fullerton, P M, Proceedings of the Royal Society of Medicine, 1969, 62, 201.

Weber, K, and Osborn, M, fournal of Biological Chemistry, 1969, 244, 4406.

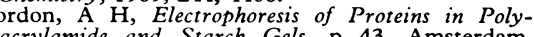
acrylamide and Starch

Gell, P G H, Coombs, R R A, and Lachmann, P J, Clinical Aspects of Immunology, 3rd edn. Oxford, Blackwell Scientific, 1974 .

\section{Steroids and hypostatic eczema}

SIR,-I want to thank Drs S Selwyn and P W M Copeman for their clarifying remarks on the treatment of patients with hypostatic eczema with Miol lotion and cream (14 February, $\mathrm{p}$ 399).

One explanation of the fact that I have seen adverse effects of treatment with strong steroids only in exceptional cases of this condition might, of course, be the choice of steroid. Approximately $90 \%$ of my patients were treated with betamethasone valerate or betamethasone dipropionate. In controlled studies we also used other steroids, and noted a temporary erythema of the skin and a burning sensation after, for example, fluclorolone acetonide or flumethasone.

Drs Selwyn and Copeman are concerned about the use of antibiotics in skin medicaments without bacteriological monitoring. I entirely agree that antibiotics are very seldom needed, either in leg ulcers or hypostatic eczema. Fairly extensive investigations in our clinic have shown not only that an antibiotic may change the growth pattern entirely but also that healing progresses independently of the bacterial flora. Skin conditions on the basis of venous incompetence of the leg should not be treated with antibiotics, either locally or systemically, unless there is a severe clinical 